Please send trade news information and

illustrations to Arveen Bajaj at the BDJ, Nature

Publishing Group, The Macmillan Building,

4-6 Crinan Street, London N1 9XW.

Trade news is provided as a service to readers

using text and images from the manufacturer,

supplier or distributor and does not imply

endorsement by the BDJ. Normal and prudent

research should be exercised before purchase or

use of any product mentioned.

\section{Fast strong temporaries}

Dentsply has recently introduced Integrity to the market, the complete solution for temporary crown and bridge procedures, which includes the Integrity provisional material in $15 \mathrm{~g}$ mini-syringes and Integrity TempGrip Cement 9 g automix.

Integrity provisional C\&B material offers fast, strong temporaries with aesthetics in combination with convenient, hygienic and easy handling and bonding to itself for easy repairs. Integrity polishes to a natural lustre and will be offered in four different shades with fluorescence. The mini-syringe delivery combines convenience and ease of use.

The Integrity TempGrip temporary crown and bridge cement completes the range. It has a low film thickness and high compressive and flexural strengths

\section{Accident alert}

The Eclipse range of first aid, eye wash and biohazard kits give you everything you need to deal with accidents. The first aid kits are Health and Safety Executive compliant and cover either 10 or 20 person premises.

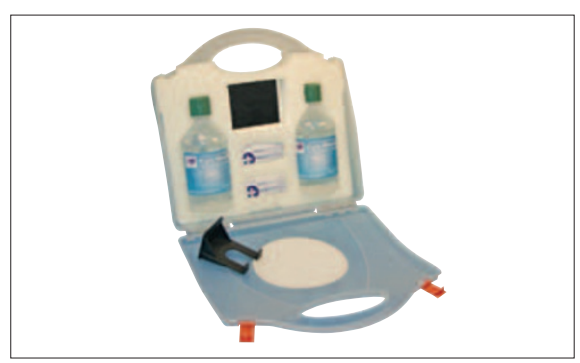

\section{Enhancing disinfection}

Quality Endodontic Distributors Limited is the UK distributor of the complete range of Vista endodontic products and solutions, which are supplied in unit

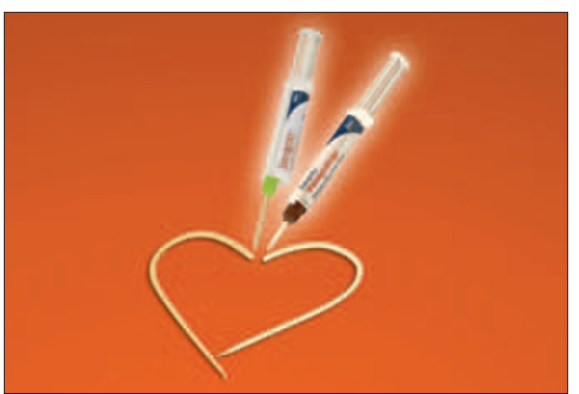

with a creamy and non-drip flow and supports easy removal of the provisional because the cement stays in the crown and not on the tooth. A short setting time helps to save time for the dentist and the patient.

Because of its non-eugenol character, the product shows a reliable performance with the ability to work with resin-based materials. It is offered in an automix syringe that assures correct mixing.

Reader response number 50

The eye wash kit enables you to rinse away blood, saliva and other dental debris. Each kit includes a carry case, two $500 \mathrm{ml}$ bottles of sterile eye wash, eye pad dressings and a mirror.

The Eclipse biohazard kit makes sure there is no mess and no fuss - sprinkle the super absorbent granules onto the vomit or other mess and wait two minutes until the spill solidifies. Use the scoop to place the waste into the disposal bag. Each pack also contains vinyl gloves, an apron and disinfectant spray.

Until the end of September, you will receive the biohazard kit free when you buy the first aid and eye wash kits at a saving of $£ 13.50$.

Reader response number 51

doses as well as traditional bottles. Vista 17\% EDTA Solution allows the removal of the smear layer and dentine 'mud'. This enhances disinfection and prepares the dentine walls for advanced adhesion of filling materials. It is supplied in $1.2 \mathrm{cc}$ syringes, and $120 \mathrm{ml}$ or $480 \mathrm{ml}$ bottles.

Reader response number 52

\section{Managing the business side of dentistry}

Designed to help run the financial and business side of dentistry, Kodak BackOffice Software from PracticeWorks is a new range of software and services being launched at this year's Dental Showcase on stand H11.

The software covers the eight critical management areas all dental practices must address - staff records, stock control, purchase ledger, payroll, nominal ledger, petty cash, bank and reports. A user-friendly comprehensive profile of each staff member can be created simply and quickly within their record, recording everything from personal details and emergency contact details to working patterns, holiday entitlement and payroll information.

Back-Office Staff Records will also be able to record time sheet information. A template of the individual's usual working hours will be created and the user will then be able to note any time taken off for sickness or holidays. In addition Back-Office will provide you with all the critical documentation you need for the human resources side of your business. Reader response number 53

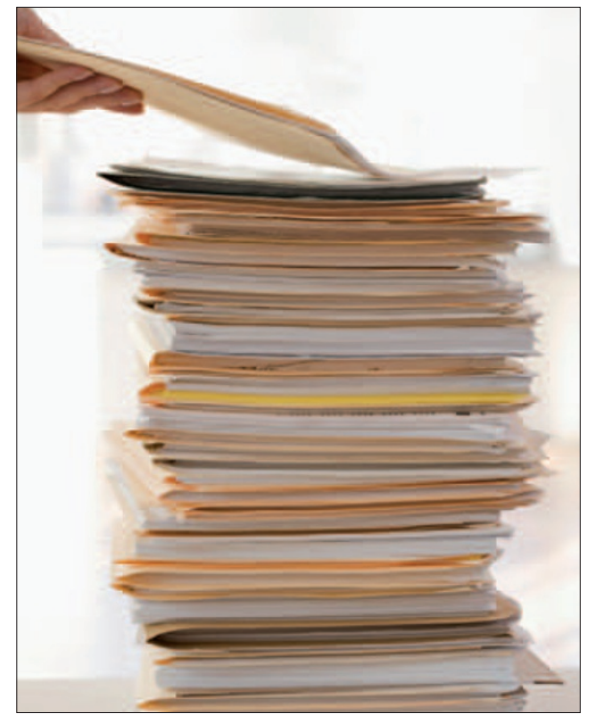




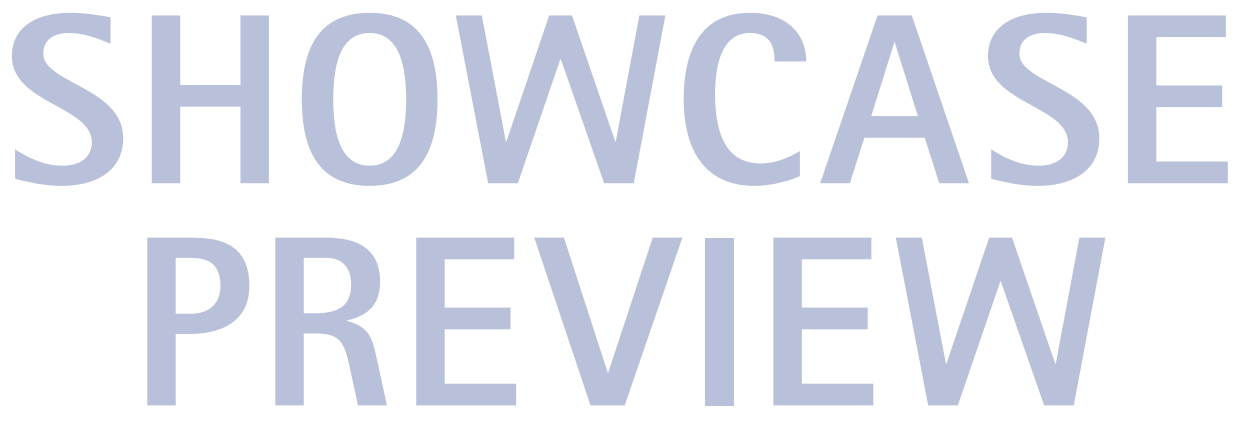

\section{CPD at exhibition}

This year's British Dental Trade Association (BDTA) Dental Showcase takes place at the NEC Birmingham on 1820 October 2007. You can register for your complimentary entry ticket now on the official dental showcase website www.dentalshowcase.com or call the telephone hotline on 01494729959. Advance registration closes 30 September 2007. On the day registration is $£ 10$ per person and Showcase takes place in halls 6 and 20 .

The BDTA also offers you CPD hours for your time spent at the exhibition. To claim CPD hours, ensure that your badge is scanned by staff at the entrance of the exhibition hall on arrival and at the exit on leaving the show for the final time.

A certificate showing the hours spent at the show will be posted to the address given at the time of ticket registration approximately 28 days after the event. The certificate will be accompanied with

\section{Interior developments}

Admor has expanded its portfolio with the introduction of many new interior development products like its dental canvas art range and the latest in internal and external surgery signage.

The company also offers reception area furniture and cabinetry, all designed to

\section{Convenient dispensing}

You will have the opportunity to handle several recent introductions to Kerr's range at Showcase on stand J04. You will be introduced to Demi, the new wandstyle, ergonomic LED curing light with breakthrough Periodic Level Shifting (PLS) technology that delivers a true five-second cure for universal composite a feedback form, which will give you an opportunity to influence the way that Dental Showcase is run in the future.

You also have the opportunity to win a cute toy rabbit. All you

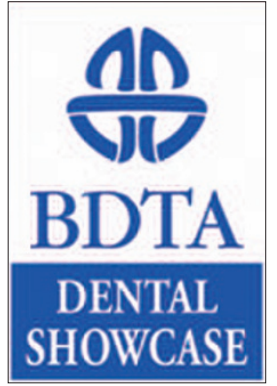

have to do as you walk around the exhibition is spot the stands displaying a small white cuddly rabbit and make a note of the stand number on which they appear on the entry form in the Official Showcase Catalogue.

When you think you have found 40 rabbits, bring the entry form to the BDTA stand by the entrance. Each day, the first 100 individuals to return correctly completed forms will win a toy rabbit to take home with them with compliments of the BDTA.

Reader response number 54

create a modern, welcoming environment. Dentists will once again be invited to take advantage of Admor's design service, backed by experience in commercial interiors.

Visitors to the Admor Stand E07 will be able to obtain a copy of the 2007 Admor Directories and a number of samples of Admor products.

Reader response number 55

\section{Toothbrush technology}

PEtG has recently launched the Oral-B Triumph SmartGuide, which contains a new microchip in the handle that communicates usage information to the user via a wireless remote display to promote optimal brushing habits.

P\&G Professional Oral Health also has an assortment of manual brushes with differing functionality and pricing so that there is one to suit everyone. The Oral-B CrossAction is the company's most popular brush and for those who want additional technology, there is the Oral-B Pulsar, a manual toothbrush with MicroPulse bristles.

Oral-B Stages, the company's children's range of toothbrushes, offers a solution for all stages of a child's development from infant through to teenager. To find out more as well as taking advantage of an exclusive Showcase offer visit the P\&G stand.

Reader response number 56

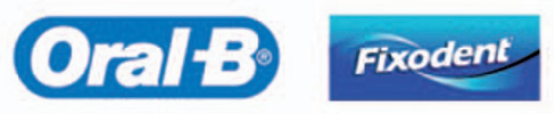

PeG Professional Oral Health

shades A3 and lighter. With PLS, Demi pulses from a baseline output of 1,100 $\mathrm{mW} / \mathrm{cm}^{2}$ to a peak of $1,330 \mathrm{~mW} / \mathrm{cm}^{2}$ for $1 / 4$ second of each one second exposure.

$\mathrm{NX} 3$ is a new generation of adhesive

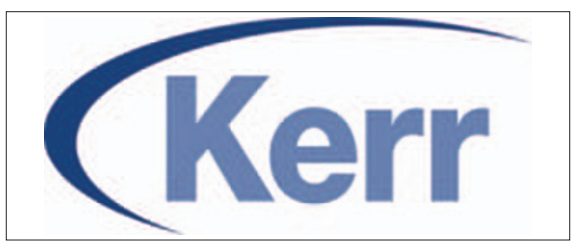

resin cement that is compatible with both total-etch and self-etch adhesives. NX3 delivers colour stability, high translucency as well as strong adhesive properties.

A dual-cure automix syringe provides a convenient dispensing system, and a light cure base cement is available for those requiring unlimited working time. To provide even more versatility, matching tryin gels perfectly colour-matched to NX3 composite are available in five shades. Reader response number $\mathbf{5 7}$ 


\section{Protects and strengthens}

GC will be demonstrating the very latest technology with Fuji IX Extra and G-Cem at this year's exhibition. Fuji IX Extra is a packable, aesthetic glass ionomer restorative with high levels of fluoride release. The translucent material achieves a life-like appearance when used in the anterior region.

G-CEM is a dual-cure self-adhesive universal resin cement in a capsule, designed for adhesive luting of allceramic, metal or composite indirect restorations. With CAD-CAM and metalfree restorations becoming so popular, G-CEM has been developed with the aim of combining improved handling and self-adhesion of conventional cements with the superior mechanical properties, adhesion and aesthetic qualities of resin cements.

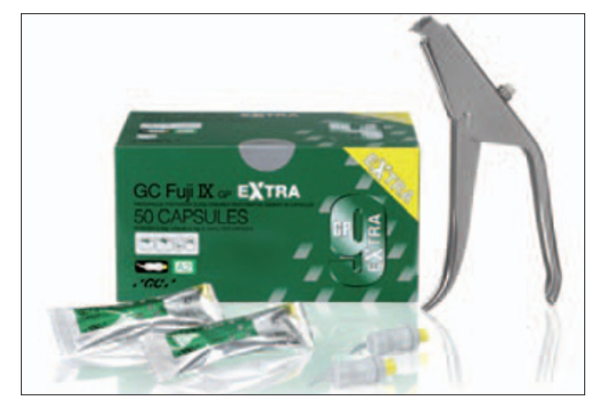

To give your glass ionomer restorations the very best start in life, G-Coat Plus nano-filled coating protects and strengthens immediately, maximising their final hardness and preventing moisture contamination during the crucial initial setting phase.

Finally, new MI Paste Plus topical dental crème combines the benefits of Tooth Mousse, with 900 ppm of a unique, patented form of fluoride developed specifically for high-risk patients.

Reader response number 58

\section{Precision fit metal-free restorations}

Renishaw's incise is an innovative yet very affordable dental CAD/CAM system that uses new measurement technology, focusing on accuracy throughout production. This creates ceramic restorations that are aesthetically pleasing and have Renishaw's guarantee that they will provide a precision fit.

It is the only metal-free CAD/CAM system on the dental market that certifies the quality of fit for manufactured ceramic restorations, using revolutionary manufacturing and measurement technology. incise is affordable and has benefits for both dentists and dental

\section{Prevention of bruxism}

The e-motion company will be displaying its NTI-tss product for the prevention of bruxism and the treatment of temporomandibular disorders (TMD) at Showcase. Nociceptive Trigeminal Inhibition-tension suppression system (or NTI-tss for short) is now available to UK practitioners.

Due to its ease of use and low cost, the NTI is also a very convenient, time-saving and low risk instrument for the general dentist to start treating functional disorders and to prevent bruxism-related symptoms and consequences eg in prosthetics and implantology.

The prevention and treatment of chronic tension headaches and migraines can add a new opportunity for practice building and enlarge the therapeu- technicians. Visit Renishaw plc on stand B09 for further information.

Reader response number 59

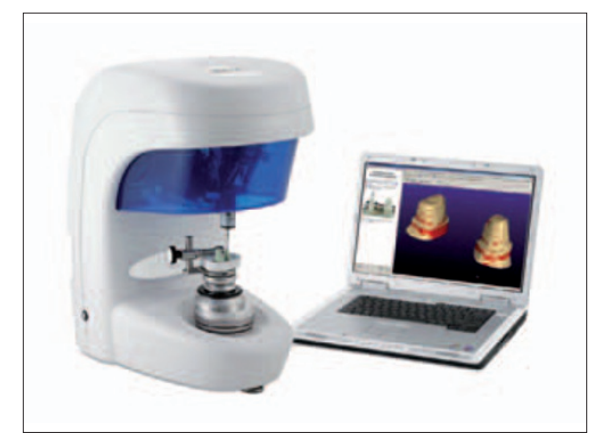

tic environment of the dental practice towards an interdisciplinary approach.

For the patient, besides alleviating the pain and greatly improving the quality of life, the NTI can save time and money. Visit stand L05 for a product demonstration and more information.

Reader response number 60

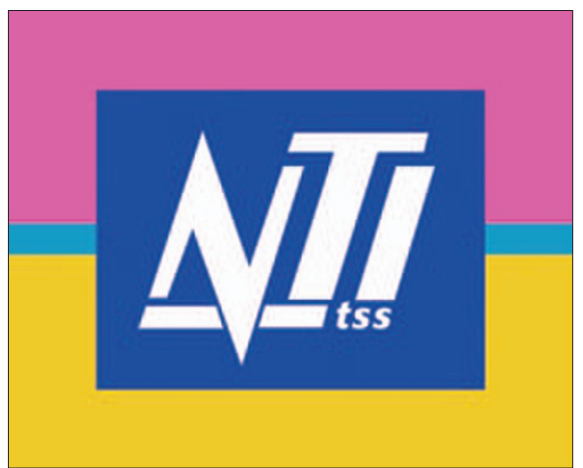




\section{Equipping the surgery}

Sirona equips dental practices, clinics and laboratories with the tools they need to effectively address the future. In addition to their range of treatment centres, handpieces, intraoral and panoramic Xray units, Sirona's products can be seen at general dealers Minerva Dental at stand S02, Henry Schein at stand G01 and Sident Dental Systems at stand F07.

\section{sirona}

The Cerec product range for clinicians will be presented by specialist companies Ceramic Systems on stand F06 and Sirona Dental Systems Ltd at stand N02. Specific inLab and inEos laboratory applications will be demonstrated by Panadent on stand Q01.

Reader response number 61

\section{Single-coat application without mixing}

Visit Heraeus Kulzer on stand R01 at Dental Showcase for a demonstration of the new Provil Dynamix Putty in the Dynamix mixing machine. Find out about the new iBond Self Etch which allows the dentist to etch, prime, bond and desensitise, without mixing and without waste, all in one single-coat application.
Other innovations from Heraeus Kulzer include the lightweight Translux Power Blue LED curing light, Flexitime flexible working time impression material and the non-bovine bone augmentation material 0stim, ideal for extraction sites.

Reader response number 62

USBCam, will be the new Schick USBCam2 intraoral camera which enables you to take images from extreme close-up to full arch without adjusting the focus.

You can learn about the new Schick Practice Support Programme which covers either Schick software and hardware or software only, and helps you minimise downtime as well as avoid unexpected repair costs. Also on show will be the Schick CDR cabled and Schick CDR Wireless cable-free sensors for intraoral X-ray, the Schick CDR SDX X-ray generator and the Schick CDRPanX digital pan unit.

Reader response number 64

\section{Drop into the GDC registration surgery}

With the legal deadline for GDC registration fast approaching, dental nurses and dental technicians must act now to ensure they are registered in time. Nurses and technicians who delay could find themselves working illegally next summer as all dental nurses and dental technicians must be registered by 30 July 2008.

The GDC has simplified the application process and introduced new streamlined application forms and at this year's Dental Showcase, it is offering an application checking and advice service at Stand Ax04.

A dedicated team of GDC staff will be on hand at their 'Registration Surgery' to answer questions, provide application forms, check applications and make sure they are complete and correct - well in advance of the July 2008 deadline.

If everything is in order they can take your completed form back to the office for processing. Completed forms and accompanying documents can be submitted by colleagues for those who cannot make it themselves.

Dental nurses and technicians who would like to submit applications at the 'Registration Surgery' need to bring certified copies of all the relevant supporting documents, including proof of identity. More information is available from the GDC website www. gdc-uk.org.

Reader response number 66

\section{Complete surgery designs}

Clark Dental will be displaying three 'complete' surgery designs featuring chairs from A-dec and Anthos and cabinetry from the ultra-modern Edarredo range at Showcase this year.

You can choose any equipment from A-dec or Anthos or opt for cabinets from Edarredo or Modwood, and with its five year finance offer you pay nothing for one year and get three years free warranty.

Payments start in year two (all credit). Clark Dental also provides a complete 'one-stop shop' solution for surgery design and equipment installation.

Reader response number 63

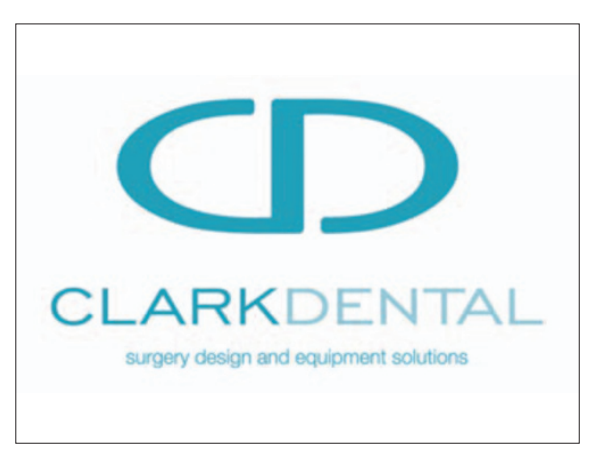

\section{Birthday celebrations}

Henry Schein welcomes everyone attending Dental Showcase on 19 0ctober to enjoy a glass of champagne and a slice of cake on stand G01 at $12 \mathrm{pm}$, as the celebrations commence for their 75th birthday.

Henry Schein will be celebrating their 75th year by exhibiting their latest equipment, products, services and innovations. Visitors can come and listen to guest speakers covering topics such as decontamination, 3D cone beam X-ray technology and laser dentistry. If you're currently a practice manager, don't miss the introduction of this year's BDPMA Career Development Grant, sponsored by Henry Schein.

Reader response number 65

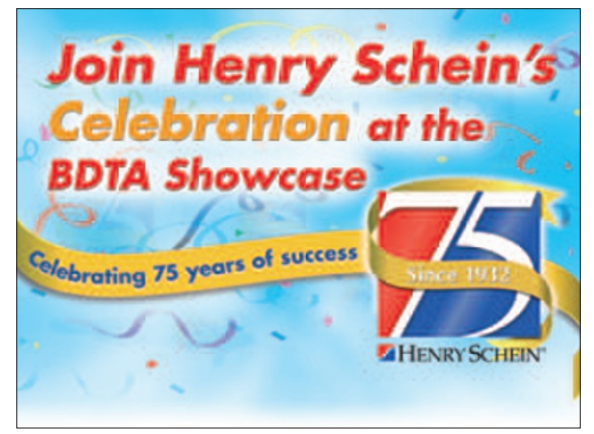




\section{New product unveiled}

Visitors to the GlaxoSmithKline Consumer Healthcare (GSK) stand U01 and T08 will have the chance to find out more about its new Corsodyl product launch. In addition visitors will also have the opportunity to learn more about the company's product portfolio, which includes Sensodyne, Poligrip, Corsodyl and the new Aquafresh kids range. The stands will also feature the

\section{High quality work clothing}

Visit Kent Express at this year's Dental Showcase to find out about a unique customer reward scheme as well as a number of additional promotions and discounts through its electronic ordering systems and direct debit payments methods.

Kent Express stocks over 20,000 products from top name manufacturers including small equipment, as well as 'Hejco', its range of high quality work clothing. Furthermore, it offers highly

\section{Choice of delivery systems}

KaVo will be launching its E80 dental unit this year. It boasts many features and benefits not otherwise available. Also being launched is the latest $\mathrm{KaVo}$ 3-D eXam imaging tool, the Gentleray 980 soft tissue laser and the Stericlave B vacuum autoclave.

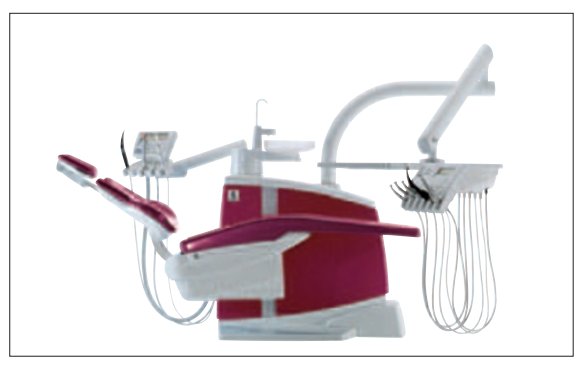

\section{Improving oral health}

Oral health company Sunstar which is active in 80 countries worldwide has now made its range available to UK dental practices and is being showcased on stand V09 at the Showcase exhibition.

The GUM brand is specifically designed to fight and prevent the local effects of periodontal disease and its impact on overall health. This collection takes a

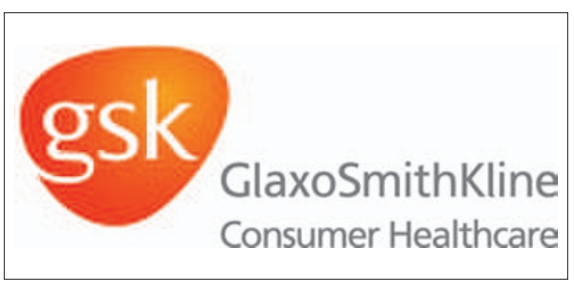

full range of support material for dental practices including educational leaflets and posters.

Reader response number 67

cost-effective and compatible quality products from its own brand portfolio.

The dedicated team at Kent Express will be on hand to discuss your business and your needs, helping you to make the most of product promotions and specials available on the day.

Reader response number 68

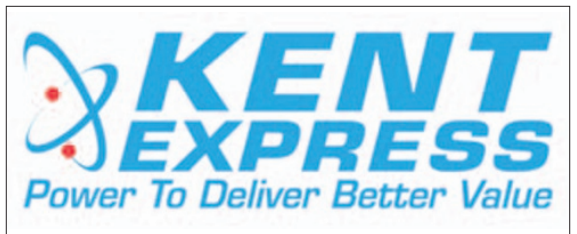

In addition, you can see a variety of dental units with a choice of delivery systems to suit all needs and budgets, including the highly economical 1056 unit and the Primus 1058 CompactChair with knee break. Multimedia options will be available to suit the individual needs of your practice.

$\mathrm{KaVo}$ will also be demonstrating its range of handpieces, which are designed to meet all clinical and economic needs and a number of innovations such as the Diagnodent Pen, a convenient easy to use laser diagnosis system and the inlab Everest CAD/CAM milling system.

KaVo Gendex will also be displaying a full range of X-ray equipment including many new innovations in digital technology. Visit stand N01 for more information.

Reader response number 70

progressive three step methodology to oral health to provide all-encompassing patient care: a broad sweep of toothbrushes, a flexible collection of flossing products and a diverse range of dental accessories from interdental brushes to toothpastes and from mouth rinses to orthodontic waxes.

The Company is now actively seeking dental professionals to take part in a campaign called 'My 3-Steps'. The campaign centres around advice from

\section{Ultraviolet technology}

Visitors to the Sonicare stand at K02 have the chance to brush with the new sonic toothbrush FlexCare. It is 30\% smaller, $16 \%$ lighter and has $80 \%$ less vibration than the Sonicare Elite with FlexCare.

Philips has also engineered the first combined UV sanitiser and toothbrush charger, which helps to safeguard brushheads against potentially harmful microorganisms. The FlexCare Sanitiser helps to eliminate germs for a clean, hygienic brushhead in a ten minute cycle using ultraviolet technology which helps to neutralise microorganisms, preventing them from reproducing.

Reader response number 69

\section{Surgery storage solutions}

Visit A-dec on stand K01 to experience its range of surgery solutions. A-dec will have six fully-functioning treatment bays featuring the A-dec 500 range on display, the most recent side and 12 o'clock delivery options and a comprehensive array of cabinetry.

The A-dec Preference cabinetry selection provides a multitude of storage solutions as well as a choice of highly innovative Infection Control Centre (ICC) modules - a central sterilisation concept pioneered in America.

Join the A-dec team to discuss the latest advances in dental equipment ergonomics and see how it can offer comprehensive solutions to your surgery requirements.

Reader response number 71

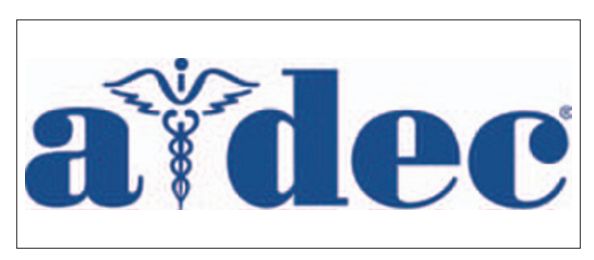

key opinion leaders taking a stepped approach to treating oral health issues including caries protection, gingival bleeding, oral malodour, sensitive teeth or helping patients after whitening or undergoing orthodontic treatments.

Sunstar has also planned an active presence at five key dental meetings between now and November 2007 where they hope to make contact with as many dental professionals as possible.

Reader response number 72 